\title{
Doenças da cavidade nasal em ruminantes no Brasil ${ }^{1}$
}

\author{
Roseane de A. Portela ${ }^{2}$, Franklin Riet-Correa ${ }^{2}$, Felício Garino Júnior ${ }^{2}$, Antônio \\ F.M. Dantas ${ }^{2}$, Sara V.D. Simões ${ }^{2}$ e Silvana M.S. Silva ${ }^{3}$ \\ ABSTRACT.- Portela R.A., Riet-Correa F., Garino-Junior F., Dantas A.F.M., Simões S.V.D. \\ \& Silva S.M.S. 2010. [Diseases of the nasal cavity of ruminants in Brazil.] Doenças da \\ cavidade nasal em ruminantes no Brasil. Pesquisa Veterinária Brasileira 30(10):844-854. \\ Hospital Veterinário, Centro de Saúde e Tecnologia Rural, Universidade Federal de Campina \\ Grande, Campus de Patos, 58700-970 Patos, PB Brazil. E-mail: franklin.riet@pq.cnpq.br \\ This paper reports diseases of the nasal cavity diagnosed in ruminants in the Veterinary \\ Hospital of the Federal University of Campina Grande, in Patos, state of Paraiba, \\ northeastern Brazil, from 2003 to 2009. During that period three cases or outbreaks of \\ diseases of the nasal cavity were reported in cattle, three in goats and nine in sheep (out \\ of 404 diseases diagnosed in cattle, 330 in goats, and 338 in sheep). At all are reported \\ one case of atopic rhinitis in cattle, seven outbreaks of conidiobolomycosis and two \\ outbreaks of rhinofacial pythiosis in sheep, two cases of protothecosis and one of nasal \\ aspergillosis in goats, and a myxoma and a fibrosarcoma in cattle. Additionally, other \\ diseases of the nasal cavity reported in Brazil are reviewed, including oestrosis, \\ rhinosporidiosis, squamous cell carcinoma, and enzootic ethmoidal tumor.
}

INDEX TERMS: Rhinitis, conidiobolomycosis, nasal pythiosis, rhinosporidiosis, nasal aspergillosis, nasal tumors, cattle, goat, sheep.

RESUMO.- Este trabalho descreve as doenças das fossas nasais diagnosticadas em ruminantes no Hospital Veterinário da Universidade Federal de Campina Grande, em Patos, Paraíba, nos anos de 2003-2009. No período foram registrados três diagnósticos de doenças das fossas nasais de bovinos, três em caprinos e nove em ovinos (de um total de 404 diagnósticos em bovinos, 330 em caprinos e 338 em ovinos). Descrevem-se um caso de rinite atópica em bovinos, sete surtos de conidiobolomicose e dois de pitiose rinofacial em ovinos, dois casos de prototecose e um de aspergilose nasal em caprinos e um mixoma e um fibrossarcoma em bovinos. Adicionalmente, é realizada uma revisão de outras doenças das fossas nasais de ruminantes descritas em outras regiões do Brasil, incluindo oestrose, rinosporidiose, carcinoma epidermóide e tumor etmoidal enzoótico.

\footnotetext{
${ }^{1}$ Recebido em 29 de abril de 2010.

Aceito para publicação em 19 de julho de 2010 .

${ }^{2}$ Hospital Veterinário, Campus de Patos da Universidade Federal de Campina Grande (UFCG), Patos, PB 50700-000, Brasil. *Autor para correspondência: franklin.riet@pq.cnpq.br.

${ }^{3}$ Departamento de Clínica e Cirurgia, Centro de Ciências Agrárias, Universidade Federal do Piauí (UFPI), Campus da Socopo s/n, Bairro Socopo, Teresina, PI 64049-550, Brasil.
}

TERMOS DE INDEXAÇÃO: Rinites, conidiobolomicose, pitiose nasal, rinosporidiose, aspergilose nasal, neoplasias nasais, bovinos, caprinos, ovinos.

\section{INTRODUÇÃO}

As rinites dos ruminantes são um grupo heterogêneo de doenças que causam sinais semelhantes. Algumas delas como a rinosporidiose, rinite atópica e oestrose não causam a morte dos animais, mas podem causar prejuízos econômicos importantes por perda ou menores ganho de peso (Stigger et al. 2001, Ribeiro 2007). Outras como a pitiose rinofacial e a conidiobolomicose em ovinos apresentam alta letalidade (Silva et al. 2007a, Riet-Correa et al. 2008). O conhecimento das rinites causadas por diferentes agentes e de outras enfermidades não inflamatórias, como as neoplasias, e o seu diagnóstico diferencial é importante para que possam ser recomendadas medidas de controle e profilaxia. O objetivo deste trabalho foi descrever as doenças da cavidade nasal diagnosticadas em ruminantes no Hospital Veterinário (HV) da Universidade Federal de Campina Grande (UFCG) e em outras regiões do Brasil.

\section{MATERIAL E MÉTODOS}

Foi realizado um levantamento das doenças que afetaram a cavidade nasal em ruminantes diagnosticados, nos anos de 
2003-2009, no HV da UFCG, localizado em Patos, Paraíba. Para isto, foram revisados, nos arquivos da Clínica de Grandes Animais e do Laboratório da Patologia Animal do HV de Patos, os dados epidemiológicos, clínicos, terapêuticos e patológicos dos casos diagnosticados nas espécies bovina, caprina e ovina. Para o estudo histológico as amostras coletadas durante as necropsias ou mediante biópsias foram fixadas em formol tamponado a 10\%, incluídos em parafina, cortados em secções de 5-6um e corados por hematoxilina e eosina (HE). Nos casos de rinite fúngica, pitiose e rinite atópica (granuloma nasal) foram utilizadas, também, as colorações de ácido periódico de Schiff (PAS) e metenamina nitrato de prata de Gomori (GMS). Lâminas de rinite atópica foram coradas, também, por azul de toluidina. Blocos de parafina de casos suspeitos de pitiose rinofacial em ovinos foram encaminhados para o setor de Patologia Veterinária da Universidade Federal do Rio Grande do Sul para a realização do exame imuno-histoquímico para Pythium insidiosum. A metodologia para isolamento e identificação de Prototheca spp. utilizada em casos suspeitos de prototecose está descrita em Camboim et al. (2010a). Para o diagnóstico de aspergilose em um caprino o material foi semeado em Agar Sabouraud Dextrose. O fungo isolado foi identificado por microcultivo em lâminas e a identificação da espécie foi realizada conforme Martins et al. (2005).

Para a descrição de outras doenças das fossas nasais de ruminantes, não diagnosticadas no $\mathrm{HV}$, foi realizada uma revisão de casos publicados em anais e periódicos.

Quadro 1. Doenças que afetaram a cavidade nasal dos bovinos, caprinos e ovinos diagnosticadas entre os anos de 2003-2009 no Hospital Veterinário da UFCG, Patos, Paraíba

\begin{tabular}{lcccc}
\hline \multicolumn{1}{c}{ Diagnóstico } & \multicolumn{3}{c}{ Espécie / número de casos } & Total \\
\cline { 2 - 4 } & Bovinos & Caprinos & Ovinos & \\
\hline Conidiobolomicose & 0 & 0 & 7 & 7 \\
Pitiose rinofacial & 0 & 0 & 2 & 2 \\
Prototecose & 0 & 2 & 0 & 2 \\
Aspergilose & 0 & 1 & 0 & 1 \\
Rinite atópica & 1 & 0 & 0 & 1 \\
Mixoma & 1 & 0 & 0 & 1 \\
Fibrossarcoma & 1 & 0 & 0 & 1 \\
Total & 3 & 3 & 9 & 15
\end{tabular}

a Cada caso corresponde a um caso individual ou a um surto afetando vários animais.

\section{RESULTADOS E DISCUSSÃO}

De janeiro de 2003 a dezembro de 2009 foram registrados 404 diagnósticos em bovinos, 330 em caprinos e 338 em ovinos, entre necropsias e biópsias. Dos diagnósticos registrados, três $(0,7 \%$ dos diagnósticos na espécie) foram de doenças que afetaram a cavidade nasal em bovinos, três $(0,9 \%)$ em caprinos e nove $(2,6 \%)$ em ovinos. Os diagnósticos de doenças da cavidade nasal nos ruminantes estão demonstrados no Quadro1.

\section{Conidiobolomicose}

Foram diagnosticados sete surtos de rinite micótica ocasionada por Conidiobolus sp. em ovinos entre 2003 e 2009. Os Surtos 1 e 2 foram descritos por Riet-Correa et al. (2008). Alguns aspectos epidemiológicos dos surtos apresentam-se no Quadro 2.

Todos os animais apresentaram quadro clínico e patologia semelhante aos mencionados anteriormente (Silva et al. 2007b, Boabaid et al. 2008, Riet-Correa et al. 2008, Pedroso et al. 2009). O tratamento em seis dos oito ovinos doentes consistiu no uso de fluconazol na dose de $10 \mathrm{mg} / \mathrm{kg}$. Em dois ovinos foi realizada a administração de fluconazol como infusão endovenosa a cada 72 horas e nos demais ovinos a administração foi oral e diariamente. Os oito animais que morreram, foram necropsiados.

Macroscopicamente as lesões observadas nas fossas nasais foram semelhantes às descritas anteriormente (Silva et al. 2007b, Boabaid et al. 2008, Riet-Correa et al. 2008, Pedroso et al. 2009) (Fig.1A,B), exceto um ovino no qual a lesão restringia-se ao palato mole, palato duro, glote e orofaringe, sem afetar a cavidade nasal (Fig.1C). Em quatro animais as lesões eram bilaterais e em três unilaterais. Em um ovino a lesão penetrava no encéfalo através da lâmina cribiforme do etmóide. Em quatro ovinos os linfonodos retrofaríngeos estavam aumentados de volume e enegrecidos. Em um animal, lesões semelhantes às observadas nas fossas nasais foram encontradas no tecido subcutâneo da região do osso frontal e no cólon. No cólon, a massa era focal e irregular (Fig.1D), projetando-se da serosa à mucosa. No rim desse mesmo animal havia vários pontos branco-amarelados distribuídos no parênquima. No parênquima pulmonar de cinco ovinos havia nodulações protrusas, medindo $0,3-2,0 \mathrm{~cm}$ de diâmetro, às vezes

Quadro 2. Dados epidemiológicos dos surtos de conidiobolomicose diagnosticados no Hospital Veterinário, Patos, Paraíba, em ovinos, de janeiro de 2003 a dezembro de 2009

\begin{tabular}{|c|c|c|c|c|c|c|c|c|}
\hline Surtos & Raça & Idade/Sexo & $\begin{array}{l}\text { Animais } \\
\text { doentes }\end{array}$ & $\begin{array}{l}\text { Animais } \\
\text { rebanho }\end{array}$ & Mês & Ano & $\begin{array}{l}\text { Localidade } \\
\text { /Estado }\end{array}$ & $\begin{array}{l}\text { Curso } \\
\text { clínico }\end{array}$ \\
\hline 1 & $\begin{array}{l}\text { S }^{\text {ta }} \text { Inês } \\
\text { e Cariri }\end{array}$ & Adultos $/ \mathrm{NI}$ & 7 & 120 & Janeiro-Maio & 2004 & Souza /PB & 5-15 dias \\
\hline 2 & Sta $^{\text {ta ês }}$ & 18meses/M & 1 & 80 & Novembro & 2006 & Olho d' água /PB & 30 dias \\
\hline 3 & Sta $^{\text {Inês }}$ & 2 anos/M & 1 & $\mathrm{NI}$ & Abril & 2007 & Aracajú/SE & 120 dias \\
\hline 4 & Sta $^{\text {Inês }}$ & 8 meses/F & 4 & 20 & Agosto & 2008 & Paulista /PB & 35dias \\
\hline 5 & Sta $^{\text {Inês }}$ & 3 anos/F & 1 & $\mathrm{NI}$ & Setembro & 2008 & Patos /PB & 96 dias \\
\hline 6 & $S^{\text {ta }}$ Inês & 5anos/M & 1 & 80 & Julho & 2008 & $\begin{array}{l}\text { São José do } \\
\text { Bonfim/PB }\end{array}$ & 4 dias \\
\hline 7 & Sta $^{\text {Inês }}$ & 2anos/F & 1 & 60 & Julho & 2009 & Patos / PB & 1 dia \\
\hline
\end{tabular}




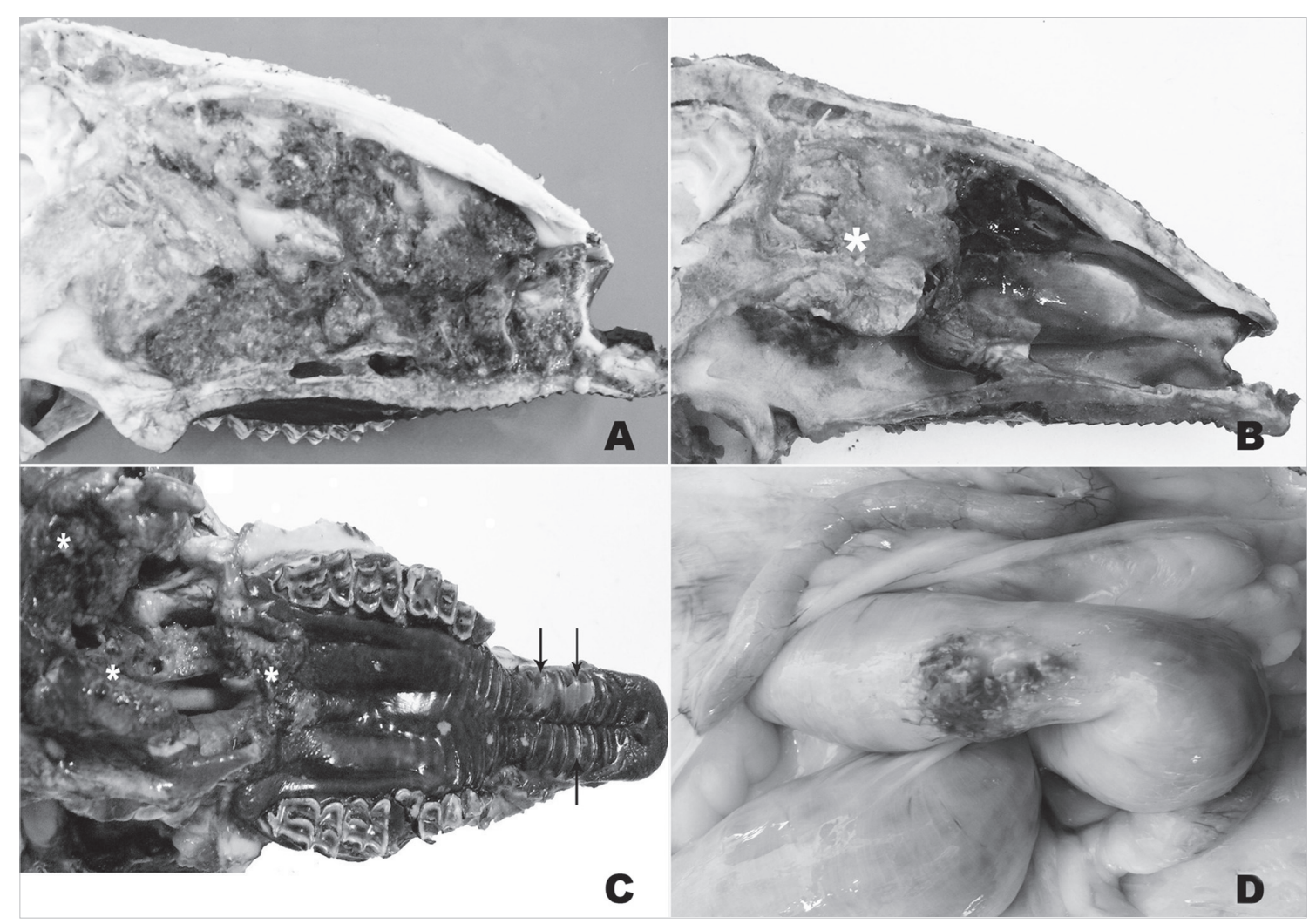

Fig.1. Ovino. Conidiobolomicose. (A,B) Corte sagital da cabeça. (A) Observa-se exsudato vermelho escuro, granular e irregular ocupando a cavidade nasal até a proximidade das narinas e nasofaringe. (B) Observa-se exsudato esverdeado ocupando a região das conchas nasais etmoidais e porções dos meatos e conchas media e ventral $\left(^{*}\right)$. Adjacente à lesão há uma área de hemorragia. (C) Vista ventral da cabeça sem mandíbula, mostrando necrose e presença de exsudato marrom nos palatos duro e mole e tecidos moles da faringe $\left(^{*}\right)$. Na região cranial do palato duro há áreas multifocais ulceradas irregulares (setas). (D) Mostra no cólon uma área focal vermelho escuro e granular com pontos amarelados.

com centro amarelado associado a algumas áreas de consolidação pulmonar.

As lesões histológicas das fossas nasais, linfonodos, pulmão, rim, encéfalo e cólon foram semelhantes às descritas anteriormente (Silva et al. 2007b, Boabaid et al. 2008, Riet-Correa et al. 2008, Pedroso et al. 2009) (Fig.2A).

Inicialmente o fungo causador da doença foi identificado como Conidiobolus coronatus (Silva et al. 2007a); porém recentemente, $C$. lamprauges foi isolado e identificado por seqüenciamento de DNA de amostras de ovinos afetados (Vilela et al. 2010). Na Paraíba, como em outras regiões, a doença ocorre durante a época de chuva ou nos primeiros meses após o final da mesma (Silva et al. 2007b, Boaibad et al. 2008, Pedroso et al. 2009). No semiárido a época das chuvas ocorre entre os meses de março a junho. Nos surtos aqui descritos como em outros trabalhos (Silva et al. 2007b, Boabaid et al. 2008) a letalidade foi de $100 \%$ e o tratamento foi ineficiente, o que sugere a eutanásia nos animais afetados. Em humanos o tratamento da coniodiobolomicose com iodeto de potássio pode apresentar recidiva e a utilização de itraconazol, cetoconazol ou anfotericina $\mathrm{B}$ por período prolongado, de seis meses a um ano, é eficiente (Nayak et al. 2004). Segundo Riet-
Correa et al. (2008) as falhas no tratamento podem ser devidas a que, por se tratar de uma lesão indolor, os animais somente apresentam sinais quando a doença está muito avançada.

\section{Pitiose rinofacial}

No HV ocorreram dois surtos de rinite por Pythium insidiosum nos anos de 2003 -2009. O Surto 1 ocorreu em março de 2006 acometendo um ovino do município de São José de Espinharas no estado da Paraíba e está descrito em Riet-Correa et al. (2008). O Surto 2 afetou um ovino, sem raça definida, com quatro anos de idade em agosto de 2007 no município de Patos, Paraíba. Na propriedade haviam outros 92 animais criados semi-intensivamente com acesso a água de poço. Os sinais clínicos foram semelhantes aos descritos anteriormente (Santurio et al. 2008, Souza et al. 2008, Riet-Correa et al. 2008). O animal foi tratado com fluconazol oral $(10 \mathrm{mg} / \mathrm{kg})$ por três períodos de oito dias consecutivos, com descanso de cinco dias, perfazendo um total de 42 dias de tratamento. Foi realizada ainda terapia de suporte com antibioticoterapia, complexo vitamínico e limpeza das narinas com solução fisiológica e clorexidine a $2 \%$. No final do tratamento o animal estava recuperado. 


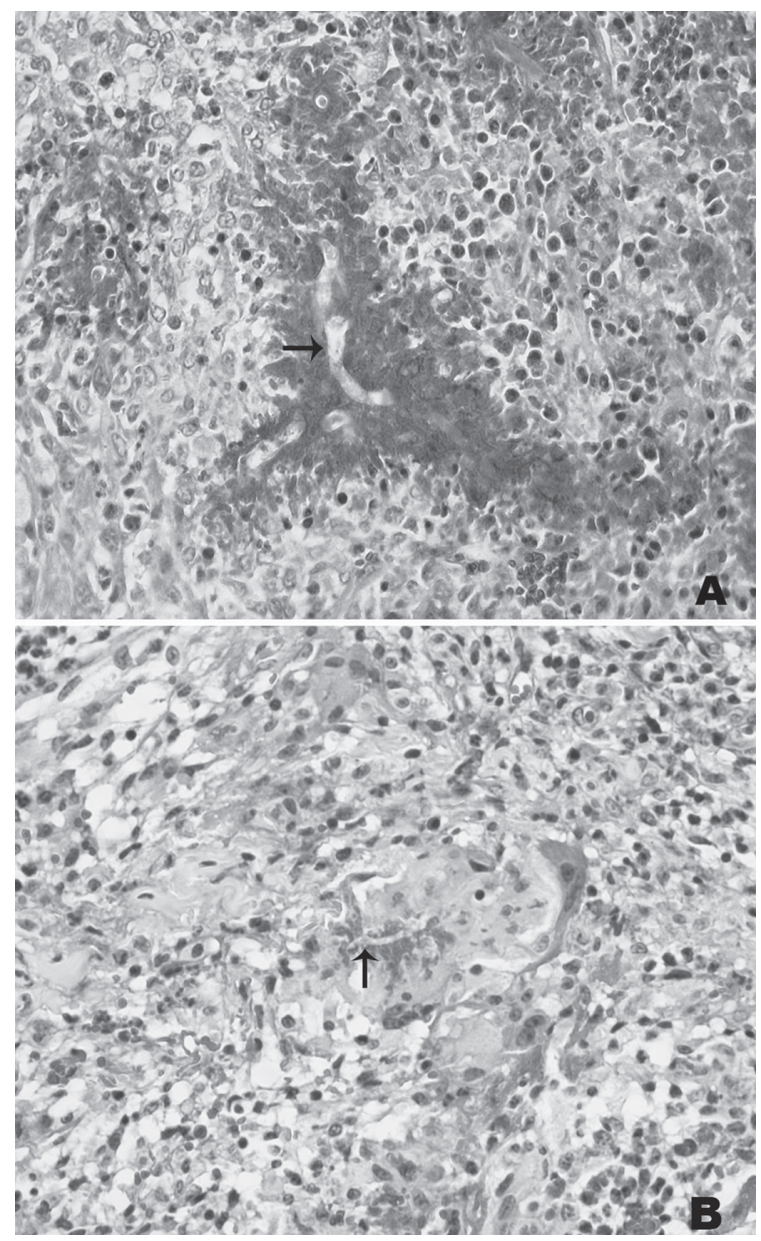

Fig.2. (A) Ovino. Conidiobolomicose. Reação histológica da conidiobolomicose mostrando hifa lar-

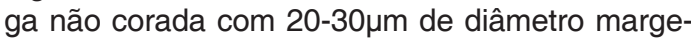
ado por abundante material Splendori-Hoeppli (seta). HE, obj.40x. (B) Ovino. Pitiose rinofacial. Reação histológica da pitiose rinofacial mostrando hifa não corada, delgada com 7-10um de diâmetro (seta) margeada por escasso material Splendori-Hoeppli e por células inflamatórias, principalmente mononucleares incluindo células gigantes. HE, obj.40x. Nas duas figuras, com o mesmo aumento, além da marcada di-ferença na largura das hifas, observa-se diferente quantidade de material de Splendori-Hoeppli: reduzido ao redor do Pythium e abundante ao redor do Conidiobolus.

As lesões histológicas observadas em uma biópsia caracterizaram-se por áreas de necrose multifocais a coalescente contendo ao centro hifas de 7-14um de diâmetro, algumas com brotamento em ângulo reto, rodeadas por escasso material Splendori-Hoeppli (Fig.2B). Havia infiltrado inflamatório composto principalmente por neutrófilos, macrófagos e células gigantes margeando a área de necrose e disperso associado à proliferação de tecido fibroso. Na mucosa havia extensas áreas de ulceração e hemorragia. A amostra enviada à UFRGS foi positiva para Pythium insidiosum pela imuno-histoquímica.
A pitiose rinofacial apresenta algumas semelhanças com a conidiobolomicose. Para o diagnóstico diferencial entre ambas, além da localização da lesão é importante a observação histológica dos dois agentes (Fig.2A,B). A ocorrência das duas doenças geralmente é no período chuvoso ou após o final do mesmo, no entanto podem ocorrer surtos na época de seca (Riet-Correa et al. 2008, Santurio et al. 2008). Outras características epidemiológicas, como o aparecimento de casos esporádicos ou surtos afetando vários ovinos, ocorrem, também, nas duas doenças. Ambas enfermidades afetam ovinos de diversas idades e podem ter um curso clínico variável, de uma semana até 60-90 dias (Souza et al. 2008, Santurio et al. 2008). Outros autores descrevem, na conidiobolomicose, um curso clínico de 7-35 dias (Silva et al. 2007b, Riet-Correa et al. 2008, Pedroso et al. 2009) ou até 56 dias (Boabaid et al. 2008), menor do que observado neste trabalho. Essa diferença poderia ser devida ao tratamento realizado, que apesar de não ter sido eficiente pode ter aumentado o curso clínico da enfermidade. Como observado neste trabalho o tratamento da conidiobolomicose é ineficiente, enquanto que o tratamento da pitiose pode ser eficiente. Em uma fazenda no Mato Grosso onde a doença é endêmica, a proprietária trata com sucesso os casos de pitiose administrando $1 \mathrm{~g}$ diária de iodeto de potássio por via oral desde a observação dos primeiros sinais até o desaparecimento dos mesmos (Colodel 2009).

\section{Prototecose}

No HV foram diagnosticados dois casos de prototecose nasal em caprinos que foram descritos por Macêdo et al. (2008a) e Camboim et al. (2010b). A Prototecose caracteriza-se por ser uma doença crônica, lentamente progressiva, que afeta caprinos imunologicamente competente causando lesões multifocais ulcerativas, piogranulomatosas e necrotizantes na mucosa e junção mucocutânea das narinas e pele da face (Camboim et al. 2010 ${ }^{\mathrm{a}}, \mathrm{b}$ ).

\section{Aspergilose}

No HV, em março de 2009, deu entrada uma cabra SRD, de três anos de idade, com histórico de secreção nasal, alterações respiratórias e intolerância ao exercício há três meses. Clinicamente apresentava respiração ruidosa, secreção nasal muco purulenta principalmente na narina direita, redução do fluxo de ar nas narinas, bochechas infladas durante a expiração e leve protrusão do globo ocular direito. Havia nódulos nas narinas e cavidade nasal com pontos esbranquiçados e aumento de volume na pele da região do septo nasal, formando duas nodulações coalescentes (Fig.3A). Seis nódulos com superfície acinzentada medindo $0,3-1,0 \mathrm{~cm}$ de diâmetro eram observados nas oreIhas, sendo três em cada orelha. O maior nódulo, localizado na aurícula, apresentava-se ulcerado (Fig.3B) e a superfície de corte era de coloração amarelada. O linfonodo pré-escapular direito estava aumentado de volume. Foram realizados biópsia e exame microbiológico do fragmento de pele e swab nasal. O animal morreu 10 dias após a internação. Na necropsia foi observada, ao corte sagital 


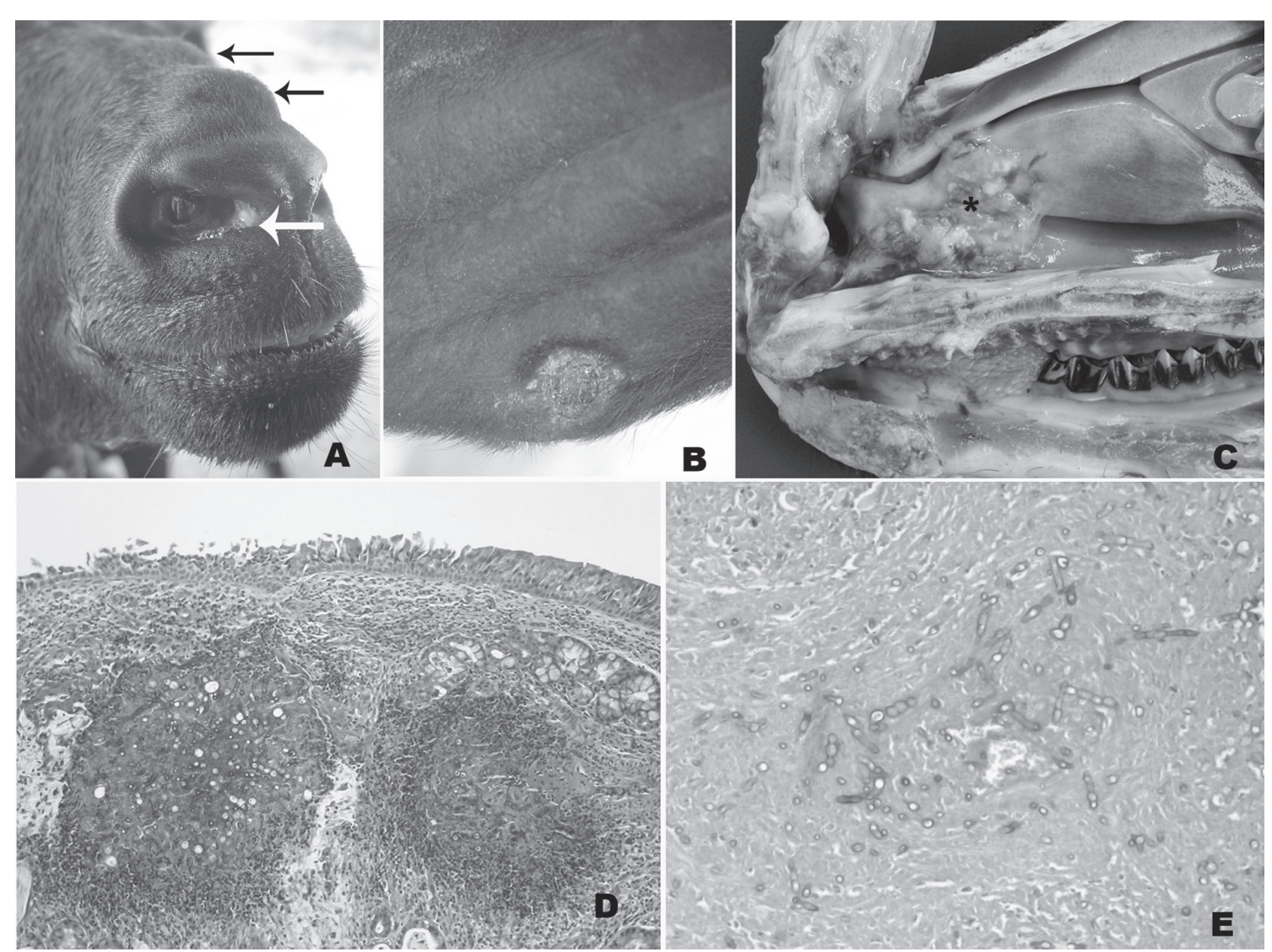

Fig.3. Caprino. Aspergilose nasal. (A) Observa-se nódulo esbranquiçado no canto medial da narina e nodulações na pele (setas). (B) Observa-se área ulcerada na borda da aurícula de $1 \mathrm{~cm}$ de diâmetro. (C) Corte sagital da cabeça mostrando uma lesão coberta por exsudato amarelado na cavidade nasal $\left.{ }^{*}\right)$. (D) Na mucosa observam-se áreas multifocais de necrose margeadas por células inflamatórias polimorfonucleares e, ao centro, hifas em cortes transversais e longitudinais. HE, obj.10x. (E) Observam-se hifas em cortes longitudinais e transversais, septadas, com paredes bem coradas e espessas e ocasionais dilatações bulbosas, com ausência de material Splendori-Hoeppli. PAS, obj.40x.

da cabeça, a presença bilateral de exsudato amarelado com áreas irregulares e esbranquiçadas proeminentes, se estendendo do vestíbulo nasal à região cranial das conchas e meatos dorsais e ventrais, incluindo o septo nasal (Fig.3C). Havia secreção seromucosa e edema periocular. Histologicamente observaram-se áreas multifocais de necrose com centro eosinofílico contendo inúmeras hifas com 5-30 $\mu \mathrm{m}$ de diâmetro, septadas, coradas basofilicamente em cortes longitudinais e transversais, com ramificações em ângulo agudo e ocasionais dilatações bulbosas apicais junto a restos celulares e neutrófilos, margeado por uma frouxa organização de fibroblastos, macrófagos epitelióides, linfócitos, raras células gigantes e eosinófilos (Fig.3D). Não havia material de Splendori-Hoeppli. Pelo PAS observaram-se as paredes das hifas bem coradas, espessas e com ausência de material de Splendore-Hoeppli (Fig.3E). O fungo isolado em Agar Sabouraud Dextrose foi identificado como Aspergillus niger.

A aspergilose nasal como rinite primária ou em associações com sinusites geralmente acomete cães (Caswell \& Williams 2007), gatos (Barachetti et al. 2009) e eqüinos (Kendall et al. 2008) em várias partes do mundo, porém é considerada rara em outras espécies (Caswell \& Williams 2007). Não foram encontradas referências descrevendo aspergilose nasal em ruminantes. No Rio Grande do Sul foi descrita em bovinos a aspergilose pulmonar, conhecida como bola fúngica (Riet-Correa et al. 1983).

A aspergilose ocorre pela inalação de esporos, embora os animais debilitados, imunocomprometidos ou ainda submetidos à antibioticoterapia prolongada estejam sob particular risco (Caswell \& Williams 2007). No caso do caprino, o animal começou a apresentar os sinais clínicos numa época extremamente seca com escassez de pastagem, porém não foi determinado o fator desencadeante da doença neste caso. O quadro clínico deste caso de aspergilose nasal em caprino é muito semelhante ao observado na prototecose nasal (Macedo et al. 2008a, Camboim et al. 2010a,b), sendo possível o diagnóstico diferencial somente pelo exame histológico e microbiológico. Para o tratamento da aspergilose nasal em cães e cavalos, vários graus de sucesso foram alcançados com o uso de enilcoInazol tópico em lavagens diárias em concentrações não superiores a $2 \%$, através de cateteres alocados cirurgicamente em local debridado (Kendall et al. 2008). 


\section{Criptococose}

No Brasil, dois casos de criptococose nasal foram relatados por Pereira et al. (2005) no estado de São Paulo e Silva et al. (2009) em Pernambuco. Ambos afetando ovinos da raça Santa Inês que apresentavam dispnéia, secreção nasal mucopurulenta de odor fétido e presença de massa na fossa nasal direita que se estendia pelos seios e meatos comprimindo o septo. Essa massa era caracterizada por formações nodulares polipóides de consistência friável e hemorrágicas. No relato descrito por Silva et al. (2009), o ovino apresentou agravamento da lesão após 31 dias e morreu durante o procedimento cirúrgico na tentativa de desobstrução nasal. No estudo histológico observaram-se áreas extensas de necrose com miríades de estruturas arredondadas ou ovaladas, leveduriformes, com parede fina corada basofílicamente e medindo cerca de 5,0-20ìm de diâmetro. Circundando as leveduras verificouse um halo claro não corado pela hematoxilina e eosina, dando um aspecto característico de "bolha de sabão", que corresponde à cápsula mucinosa do fungo, que é corada pelo alcian blue. $\mathrm{O}$ exsudato inflamatório era escasso e formado quase que exclusivamente por macrófagos (Silva et al. 2009). Anteriormente as únicas formas de criptococose descritas em ovinos eram a pulmonar (Dacorso \& Chagas 1957) e a mastite (Shnawa \& Nigam 1987). A doença é comum em gatos e cães causando rinite, lesões de pele da cabeça e nariz, meningite, lesões oculares e lesões sistêmicas (Castellá et al. 2008) e ocorre também em eqüinos, bovinos e caprinos afetando principalmente 0 sistema respiratório (Caswell \& Williams 2007).

\section{Rinite atópica}

A doença ocorreu em novembro de 2003 em um Touro Indu Brasil com quatro anos de idade, proveniente do município de São Jose do Egito, Estado de Pernambuco. A propriedade possuía um rebanho de 100 animais criados em pasto nativo e suplementados em confinamento com cama de galinha. O animal apresentava, há três meses, sangramento nasal bilateral. No exame físico detectou-se uma massa amarelada à esbranquiçada obstruindo parcialmente o interior da cavidade nasal. Em fragmentos retirados da cavidade nasal por biópsia foi observado histologicamente na mucosa acentuado infiltrado inflamatório composto principalmente por eosinófilos, plasmócitos e macrófagos e, em menor número, linfócitos (Fig.4A e B), associado à proliferação de tecido fibrovascular neoformado Havia hipertrofia das glândulas de Bowman, congestão dos vasos e edema (Fig.4A) na camada subepitelial. Os epitélios olfatórios e respiratórios estavam hiperplásicos com áreas multifocais de ulceração e hemorragia. Pela coloração de azul de Toluidina foram observados mastócitos compondo o infiltrado inflamatório. O diagnóstico foi baseado nos sinais clínicos, achados histológicos e resposta do animal ao tratamento com corticóide injetável e anti-histamínico oral. $O$ animal se recuperou e recebeu alta após 22 dias de tratamento. Após a regressão das lesões, não se soube se o animal apresentou recidiva.
A rinite atópica ou granuloma nasal é caracterizado pela presença de nódulos granulomatosos na mucosa nasal, ocasionados por um processo de hipersensibilidade imediata, aparentemente associada à exposição a polens ou esporos de fungos em certos tipos de pastagem (RietCorrea et al. 2007). A etiologia alérgica nos casos de rinite atópica é indicada pelo grande número de eosinófilos nas lesões histológicas, pela sazonalidade da doença e pelo desaparecimento passageiro dos sinais após o tratamento com corticosteróides. Clinicamente, os bovinos afetados apresentam corrimento nasal seroso ou seropurulento, às vezes com estrias de sangue, dificuldade em respirar e respiração ruidosa. Estes sinais podem apresentar-se

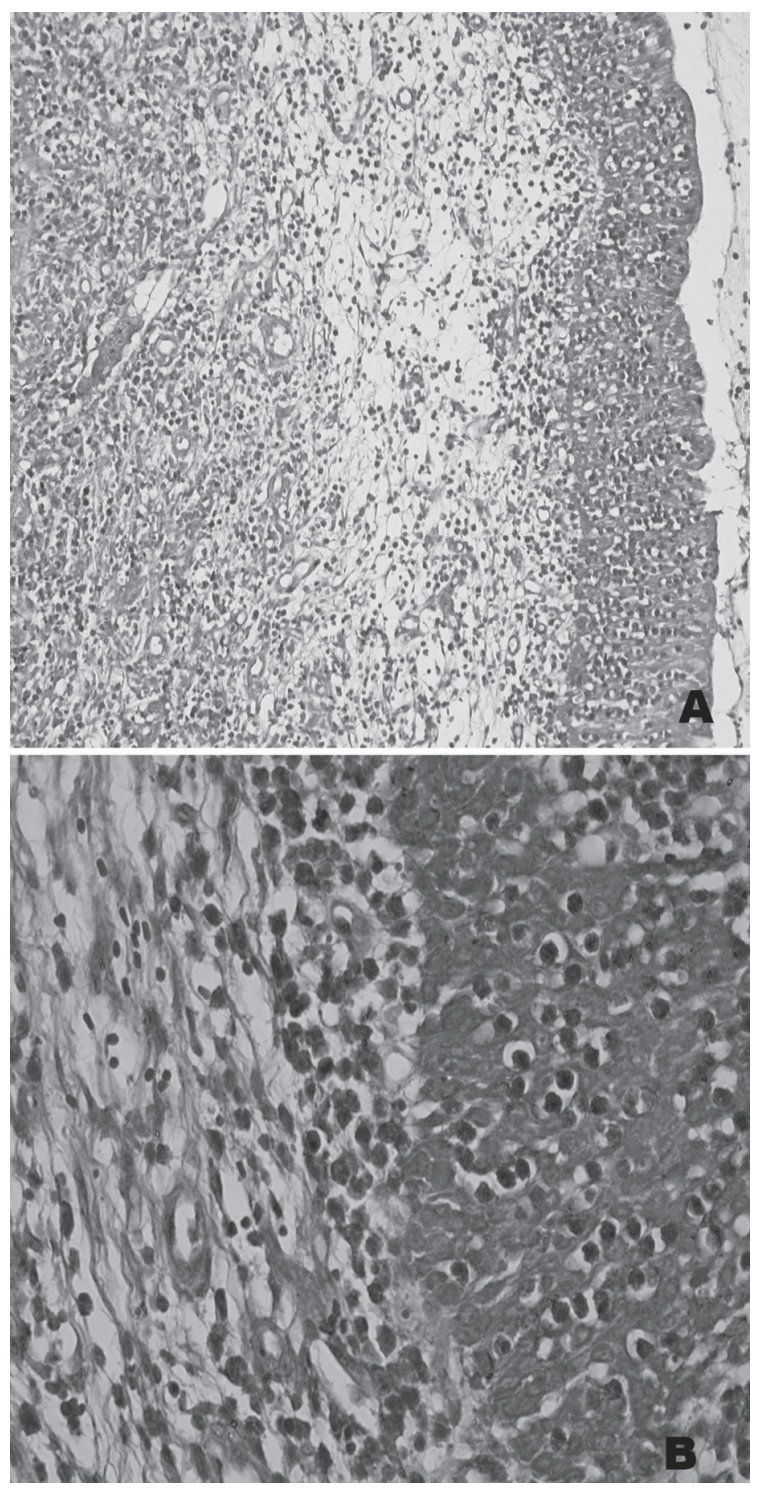

Fig.4. Bovino. Rinite Atópica. (A) Mucosa da cavidade nasal com infiltrado inflamatório, hiperplasia epitelial e edema subepitelial. HE, obj.20x. (B) Aumento de $A$, mostrando infiltrado inflamatório composto principalmente por eosinófilos e plasmócitos na mucosa. HE, obj.40x . 
de forma aguda e regridem ou exacerbam-se periodicamente (Méndez et al. 1987, Stigger et al. 2001). No Rio Grande do Sul, a doença tem sido diagnosticada afetando bovinos Jersey com idade entre 6 meses a 4 anos, principalmente na primavera e verão (Méndez et al. 1987, Stigger et al. 2001), mas outras raças leiteiras podem ser afetadas incluindo a Holandês e Guersney e ainda bovinos de corte como a raça Charolês e Aberdeen Angus (Méndez et al. 1987). No caso descrito neste trabalho a doença ocorreu em um animal Gir, não sendo encontradas referências sobre a ocorrência da mesma em raças zebuínas.

Além das doenças descritas neste trabalho, a rinite atópica em bovinos deve ser diferenciada do granuloma nasal micótico causado por Dreschslera halodes, Geotrichum sp. e outros fungos (Penhit et al. 1994, Diaz et al. 2003), que não tem sido relatados no Brasil.

\section{Rinosporidiose}

No Brasil a rinosporidiose foi descrita no Rio Grande do Sul em 1981 afetando quatro vacas em lactação de um rebanho de 200 bovinos. Clinicamente observou-se respiração difícil, estertorosa e descarga nasal mucopurulenta. As lesões na cavidade nasal eram bilaterais, observandose pólipos pedunculares medindo $2-6 \mathrm{~cm}$ de diâmetro, de coloração amarelo-esbranquiçada (Fig.5A, B). Esses pólipos apresentavam pequenas granulações esbranquiçadas e irregulares que correspondem aos esporângios do Rinosporidium seeberi. Histologicamente na lâmina própria havia infiltrado inflamatório composto por neutrófilos, macrófagos e células gigantes e linfócitos (Fig.5C,D) e com abundante tecido conjuntivo fibrovascular. Na lesão observavam-se os esporângios como microorganismos esféricos de até $300 \mu \mathrm{m}$ de diâmetro em diferentes estágios, alguns deles contendo endosporos de diferentes tamanhos. Outros aparecem como cistos vazios (Fig.5D) (Riet-Correa et al. 1983).

No Brasil, em animais domésticos de grande porte, a doença é descrita principalmente em cavalos e mulas (Londero et al. 1977, Trotte et al. 2008).

\section{Oestrose}

A oestrose é uma doença que não tem sido diagnosticada na área de influência do HV de Patos. É uma doença dos ovinos que tem sido descrita em Santa Catarina (Ramos et al. 2006), Rio Grande do Sul (Ribeiro et al. 1990) e Centro Oeste (Ribeiro 2007). Na Universidade de Brasília, de um total de 353 casos de ovinos, cinco $(1,42 \%)$ foram diagnosticados como oestrose (Borges et al. 2007). No Rio Grande do Sul em um levantamento de 361 doenças de ovinos diagnosticadas em 1990-2007, foi encontrado um só caso $(0,3 \%$ dos casos) de parasitose por Oestrus
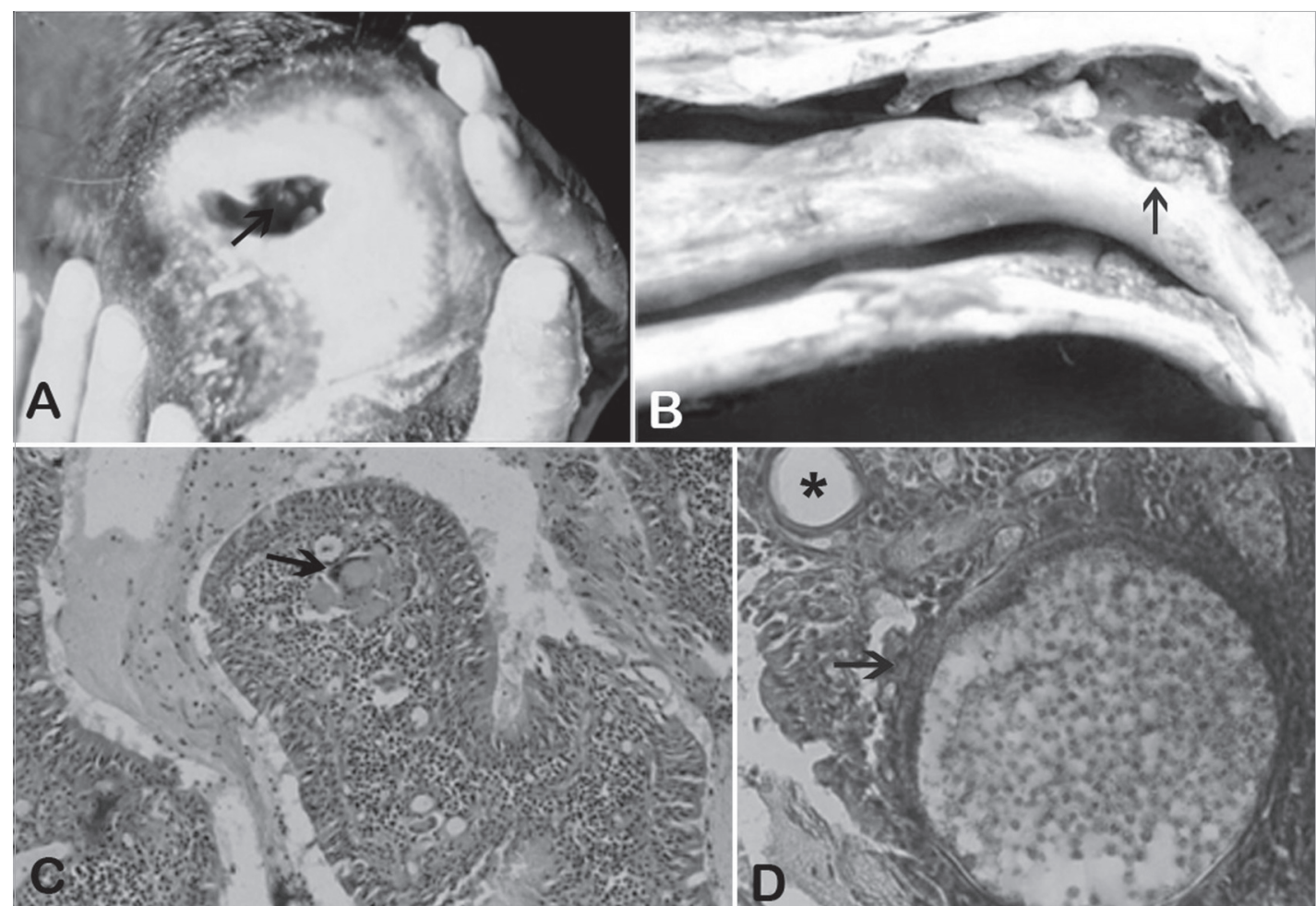

Fig.5. Bovino. Rinosporidiose. (A) Pólipos no vestíbulo nasal (seta). (B) Corte sagital da cavidade nasal. Na mucosa observam-se pólipos com granulações irregulares (seta). (C) Na lesão observase um pólipo com infiltrado inflamatório na lâmina própria composto por neutrófilos, macrófagos, linfócitos e células gigantes (seta) HE, obj.20x. (D) Observavam-se microorganismos esféricos de até $300 \mu \mathrm{m}$ de diâmetro (seta) em diferentes estágios, alguns deles contendo endósporos de diferente tamanho. Outros se apresentam como cistos vazios ( $\left.{ }^{\star}\right)$. 
ovis (Rissi et al. 2010). Como os animais não morrem em consequência da doença e os produtores conhecem os sinais clínicos, a mesma não é diagnosticada freqüentemente nos laboratórios de diagnóstico e, provavelmente, seja mais importante do que o sugerido pelo escasso número de diagnósticos e pesquisas realizadas.

A fase larval da mosca Oestrus ovis que parasita os seios nasais de ovinos e caprinos, apesar de ocorrer nas duas espécies, é mais comum em localidades onde há ovinos. Clinicamente, os animais sacodem a cabeça, coçam-se contra objetos ou em outros animais e ficam inquietos na tentativa de se livrarem das moscas adultas. A fase larval causa rinite catarral a mucopurulenta com espirros e respiração dificultosa e ruidosa (Ribeiro et al. 1990). Para o tratamento se utilizam anti-helmínticos com ação em O. ovis, incluindo ivermectinas, fosforados e closantel (Ribeiro 2007).

\section{Neoplasias}

Mixoma nasal. No HV foi atendido em dezembro de 2003 um Touro de dois anos de idade, sem raça definida, procedente do município de São José do Egito, Pernambuco. Clinicamente apresentava dispnéia, respiração estertorosa, perda de peso, aumento de volume na face lateral da narina esquerda e presença de uma massa cavidade na cavidade nasal. $O$ animal foi eutanasiado e na necropsia foi observado que a massa ocupava ambas as cavidades nasais, na cavidade nasal esquerda a massa se estendia ao seio maxilar, medindo $30 \mathrm{~cm}$ rostro-caudal e $17 \mathrm{~cm}$ dorso-ventral. Na cavidade nasal direita ocupava a região dorsal do seio nasal, medindo $10 \times 5 \mathrm{~cm}$. Macroscopicamente apresentava-se com superfície lobulada, brilhosa, branco-amarelada, cística, de consistência firmeelástica. Microscopicamente a massa tumoral era composta por células de núcleo alongado a oval com cromatina dispersa, citoplasma escasso ou em curtos prolongamentos, mergulhadas em uma matriz extracelular fracamente corada (mucinosa), com delicadas e curtas fibras arranjadas frouxamente (Fig.6A,B). Havia raras figuras mitóticas. Na face externa da massa observou-se uma extensa área ulcerada com necrose, trombos, infiltrado inflamatório, composto por eosinófilos, macrófagos e neutrófilos, e colônias bacterianas. Não foram encontrados relatos na literatura de mixomas ou mixossarcomas na cavidade nasal em ruminantes. O mixoma é uma neoplasia cutânea rara, originária de fibroblastos ou células mesenquimais multipotenciais, distinguida por sua abundante matriz mixóide rica em polissacarídeos. São tumores solitários, irregulares, localizados no tecido subcutâneo de membros e tronco de animais domésticos adultos ou idosos, principalmente cães e gatos (Goldschmidt \& Hendrick 2002). Macroscopicamente são pobremente circunscritos, na superfície de corte exibem palidez e um fluído viscoso claro. Podem ocorrer recidivas e infiltrações locais. A excisão cirúrgica é recomendada (Ginn et al. 2007), porém no caso descrito neste trabalho esta condição não era possível devido a localização.
Fibrossarcoma. Em julho de 2009 foi atendida uma vaca adulta, sem raça definida, proveniente do município de Uiraúna, Paraíba. O animal apresentava dispnéia expiratória, secreção nasal serosa bilateral, narinas dilatadas, pescoço estendido, aumento de volume na região do seio maxilar, discreta exoftalmia do olho direito (Fig.7A), míase na base do chifre direito e sialorréia $\mathrm{O}$ animal foi encaminhado à cirurgia para coleta de amostra para biópsia. Posteriormente foi diariamente submetido à antibioticoterapia e drenagem e limpeza dos ferimentos. Após sete dias de tratamento, o animal apresentou agravamento do quadro clínico e foi eutanasiado.

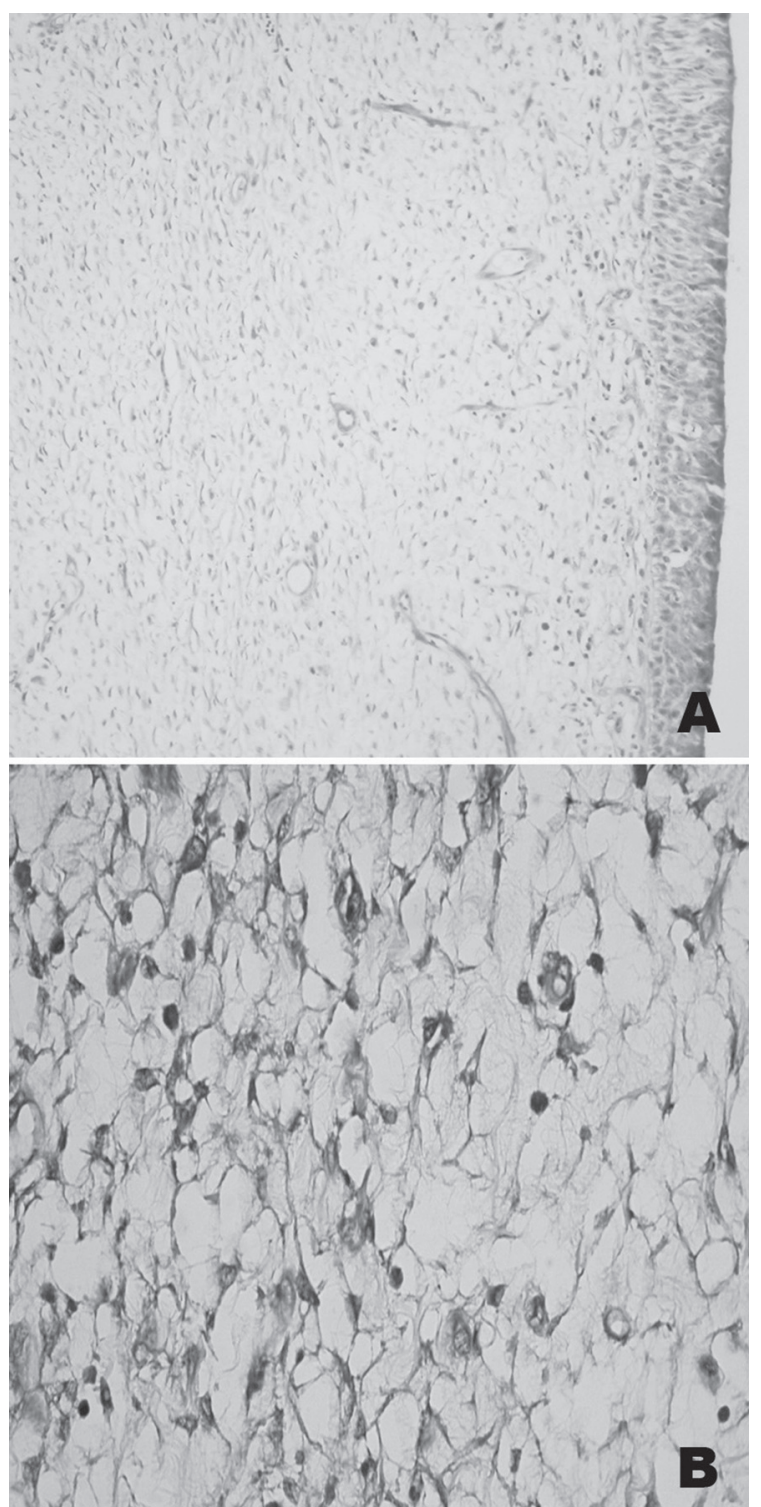

Fig.6. Bovino. Mixoma. (A,B) Histologicamente a massa tumoral é composta por células esparsas em uma matriz extracelular fracamente corada (mucinosa), com delicadas e curtas fibras arranjadas frouxamente. HE, obj.10x. (B) Observamse células de núcleo alongado à oval com cromatina dispersa, citoplasma escasso ou em curtos prolongamentos. HE, obj.40x. 

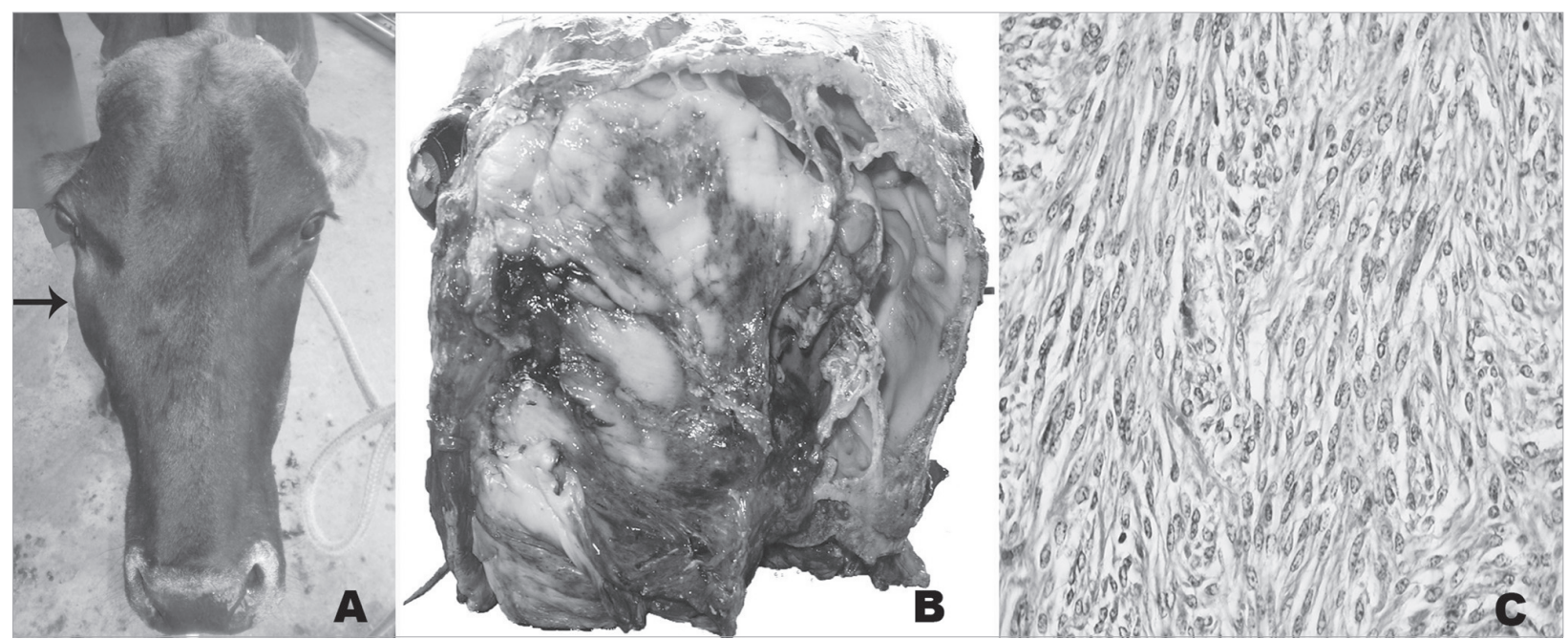

Fig.7. Bovino. Fibrossarcoma. (A) Vaca com aumento de volume na região do seio maxilar (seta) e exoftalmia do olho direito. (B) Ao corte transversal da cabeça na altura do osso frontal mostra-se uma massa amarelo-esbranquiçada entremeada a áreas avermelhadas, de aparência brilhosa, ocupando os seios frontais, maxilar, palatino e meatos e conchas nasais da cavidade direita e invadindo a cavidade nasal esquerda. (C) A histologia demonstra uma massa tumoral composta por células fusiformes de núcleo grande, vesicular, redondo a alongado com citoplasma escasso e matriz composta por fibras em diferentes direções. HE, obj.20x.

Macroscopicamente observou-se ao corte transversal da cabeça, na altura do osso frontal, uma massa esbranquiçada entremeada a áreas avermelhadas, de aparência brilhosa e de consistência mole, ocupando os seios frontais, maxilar, palatino, meatos e conchas nasais da cavidade direita. Havia destruição óssea das estruturas referidas e do septo nasal com invasão da massa à cavidade nasal esquerda (Fig.7B). Ao corte sagital e medial da cavidade nasal observou-se o comprometimento das conchas nasais etmoidais até porção média da concha nasal ventral e dorsal pela presença da massa. Histologicamente observou-se massa tumoral composta por células fusiformes de núcleo grande, vesicular, redondo a alongado com cromatina dispersa e citoplasma escasso e com bordas pouco delimitadas (Fig.7C). Havia grande quantidade de fibras conectivas, coradas em azul pelo método de tricrômico de Masson, compondo a matriz extracelular formando fascículos e feixes em diversas direções (Fig.7C). Foram observadas 2-3 figuras mitóticas por campo de objetiva 40x. O estroma era pouco vascularizado e não delimitado.

Os fibrossarcomas em ruminantes são neoplasias menos freqüentes em relação a outras espécies como cães e gatos, nos quais afetam principalmente cabeça, membros e cavidade oral (Ginn et al. 2007). Na America do Norte é relatado um caso de fibrossarcoma no seio paranasal em uma vaca (Medwel et al. 1976). No Brasil há relatos de dois casos de fibrossarcoma afetando o aparelho digestório e tegumentar em bovinos (Ramos et al. 2008). Os fibrossarcomas são neoplasias cutâneas de origem mesenquimal, características por serem malignas, geralmente de crescimento rápido e infiltrativos, porém mestátases são incomuns (Goldschmidt \& Hendrick 2002).

Tumor nasal enzoótico. No Brasil foi diagnosticada em bovinos nos estados do Rio de Janeiro (Tokarnia et al. 1972), Santa Catarina (Neves et al. 2005) e Minas Gerais (Guedes \& Nogueira 1994) e em ovinos (Driemeir \& Pedroso 2010). No estado do Piauí, em ovinos, muito diagnósticos atribuídos a ENT resultaram ser conidiobolomicose (Silva et al. 2007b). Tumor nasal enzoótico (ENT) também conhecido como adenocarcinoma enzoótico nasal é uma doença contagiosa crônica de caprinos e ovinos (De las Heras et al. 2003). Clinicamente a ENT apresenta descarga nasal persistente de mucosa à serosa ou mucopurulenta, estridor, protrusão ocular, deformidade no crânio, anorexia e dispnéia progressiva. Macroscopicamente apresentam-se como massas unilaterais ou bilaterais, pálidas, friáveis, localizadas na região dos turbinados etmoidais e adjacências. Microscopicamente pode apresentar características de adenomas à adenocarcinomas, mas geralmente é classificado como adenocarcinoma de baixa malignidade (De las Heras et al. 1988, 2003). Estudos experimentais e naturais da doença sugerem o envolvimento de um retrovírus na transmissão e crescimento do tumor (Svara et al. 2006). Casos de adenomatose pulmonar, causada pelo mesmo vírus são descritos no Rio Grande do Sul (Driemeier et al. 1998).

Carcinoma epidermóide. No HV foi diagnosticado um caso de carcinoma epidermóide nas narinas de um ovino da raça Santa Inês (Macêdo et al. 2008b). Hà 15 anos detectava-se esta neoplasia com freqüência em ovinos da raça Santa Inês de pelagem branca e as lesões se localizavam preferentemente na região periorbital e membrana nictante ou ainda na junção mucocutânea das narinas. Atualmente os casos diminuíram devido ao menor número de animais desta raça com a pelagem branca na região (Riet-Correa et al. 2003). Casos de carcinoma epidermóide do focinho e fossas nasais ocorrem também em ovinos no Rio Grande do Sul (Riet-Correa et al. 1981, Ramos et al. 2007). São 
tumores freqüentes que afetam qualquer parte do corpo, embora predominem nas áreas desprotegidas de pelo e expostas ao sol, incluindo pálpebras, orelhas, focinho e região perineal, principalmente em animais de pele despigmentada (Riet-Correa et al. 1981, Ramos et al. 2007).

Em bovinos os carcinomas epidermóides são mais freqüentes nos olhos, porém a localização desta neoplasia na base do chifre ocorre com muita freqüência e pode comprometer os seios frontais e nasais levando á corrimento nasal no seio afetado. Nos zebuínos o carcinoma epidermóide da base do chifre é economicamente importante, tendo sido observada nos estados de Minas Gerais, Mato Grosso do Sul, São Paulo (Lemos \& Nakazato 2007) e Paraná (Keller et al. 2008).

Agradecimentos.- Ao Conselho Nacional de Desenvolvimento Científico e Tecnológico (CNPq, Bolsa de Mestrado) e ao Programa de Pós-Graduação de Medicina Veterinária da UFCG pela possibilidade do desenvolvimento desse estudo. Ao Dr. Paulo V. Peixoto da UFRRJ, pela colaboração no diagnóstico histológico dos tumores.

\section{REFERÊNCIAS}

Barachetti L., Mortellaro C.M., Di Giancamillo M., Giudice C., Martino P., Travetti O. \& Miller P.E. 2009. Bilateral orbital and nasal aspergillosis in a cat. Vet. Ophthalmol. 12(3):176-182

Boabaid F.M., Ferreira E.V., Arruda L.P., Gasparetto N.D., Souza R.L., Silva M.C., Dutra V., Nakazato L. \& Colodel E.M. 2008. Conidiobolomicose em ovinos no estado do Mato Grosso. Pesq. Vet. Bras. 28(1):77-81.

Borges J.R., Moscardini A.R.C., Teixeira Neto A.R., Meirelles F., Ferreira I., Gouvêa L.V., Godoy R.F., Reis Junior J., Ribeiro L., Pereira C.S., Eneias A.C., Fonseca E.F., Perecmanis S., Guedes K.M.R., Pitombo C.A., França R.O., Rajão M. \& Castro M.B. 2007. Doenças de ovinos no Brasil Central: Distrito Federal e entorno. Quinto Congresso Latinoamericano de Especialistas en Pequeños Rumiantes y Camélidos Sudamericanos. Memorias. Associación Latinoamericana de Especialistas en Pequeños Rumiantes y Camélidos Sudamericanos. Mendoza, Argentina, p.45-47.

Camboim E.K.A., Neves P.B., Garino Júnior F., Medeiros J.M. \& RietCorrea F. 2010a. Prototecose: uma doença emergente. Pesq. Vet. Bras. 30(1):94-101.

Camboim E.K.A., Neves P.B., Garino Júnior F., Dantas A.F.M., Simões S., Azevedo E., Melo M., Mota R. \& Riet-Correa F. 2010b. Protothecosis by Prototheca wickerhamii in goats. Mycoses DOI:10.1111/j.14390507.2010.01864.x

Castellá G., Lourdes M.L. \& Cabañes F.J. 2008. Criptococosis y animales de compañía. Revta Iberoam. Micol. 25:19-24.

Caswell J.L. \& Williams K.J. 2007. Respiratory system, p.523-653. In: Maxie M.G. (Ed.), Jubb, Kennedy and Palmer's Pathology of Domestic Animals. Vol.2. $5^{\text {th }}$ ed. W.B. Saunders, London.

Colodel E.M. 2009. Comunicação pessoal (Universidade Federal do Mato Grosso, Cuiabá).

Dacorso Filho P. \& Chagas W.A. 1957. Criptococose pulmonar em caprino. Anais Col. Anat. Bras. 3:55-69.

De Las Heras M., Garcia de Jalon J.A., Balauger L. \& Badiolla J.J. 1988. Retrovirus-like particles in enzootic intranasal tumors in Spanish goats. Vet. Rec. 123:135-139.

De Las Heras M. 2003. Jaagsiekte sheep retrovirus and lung cancer. Enzootic nasal adenocarcinoma of sheep and goats. Current Topics in Microbiology and Immunology. Springer Verlag, New York, p.275280.

Diaz I.A.C., Vargas R., Apolo A., Moraña J.A., Pedrana G., Cardoso E.
\& Almeida E. 2003. Mycotic bovine nasal granuloma. Revta Inst. Med. Trop. São Paulo 45(3):163-166.

Driemeier D., Moojen V., Faccini G.S. \& Oliveira R.T. 1998. Adenomatose pulmonar ("Jaagsiekte") em ovino no Rio Grande do Sul. Ciência Rural 28(1):147-150.

Driemeir D. \& Pedroso P.M.O. 2010. Comunicação pessoal (UFRGS, Porto Alegre, RS).

Furlan F.H., Borelli V., Lucioli J., Fonteque J.H. \& Gava A. 2007. Granuloma fúngico nasal em ovinos no Estado de Santa Catarina. Anais XIII Enapave, Campo Grande, MS. (CD-Rom)

Ginn P.E., Mansell J.E.K.L. \& Rakich P.M. 2007. Skin and appendages, p.553-781. In: Maxie M.G. (Ed.), Jubb, Kennedy and Palmer's Pathology of Domestic Animals. Vol.1. $5^{\text {th }}$ ed. W.B. Saunders, London.

Guedes R.N.C. \& Nogueira R.H.G. 1994. Ethmoidal tumor in cow. Ind. Vet. J. 71(12):1236-1238.

Goldschmidt M.H. \& Hendrick M.J. 2002. Tumors of the skin and soft tissues, p 45-117. In: Meuten J.D. (Ed.), Tumors in Domestic Animals $4^{\text {th }}$ ed. lowa State Press, Ames.

Kendall A., Bröjer J., Karlstam E. \& Pringle J. 2008. Enilconazole treatment of horses with superficial Aspergillus spp. rhinitis. J. Vet. Intern. Med. 22:1239-1242.

Keller D., Rönnau M., Gusmão M.A. \& Torres M.B.A.M. 2008. Casuística de carcinoma epidermóide cutâneo em bovinos do campus Palotina da UFPR. Acta Scientiae Veterinarie 36(2):155-159

Londero A.T., Santos M.N. \& Freitas C.J.B. 1977. Animal rhinosporidiosis in Brazil: Report of three additional cases. Mycopathologia 60(3):171173.

Lemos L.S., Santos A.S.O., Silva R.M.C. \& Carvalho E.C.Q. 2005. Granuloma micótico facial de ovino. Arq. Bras. Med. Vet. Zootec. 57(1):33. (Resumo)

Lemos R.A. \& Nakazato L. 2007. Carcinoma de base do chifre, p.656658. In: Riet-Correa F., Schild A.L., Lemos R.A.A. \& Borges J.R.J. (Eds), Doenças de Ruminantes e Eqüinos. Vol.2. $3^{\underline{a}}$ ed. Pallotti, Santa Maria.

Macêdo J.T.S.A., Riet-Correa F., Dantas A.F.M. \& Simões S.V.D. 2008a. Cutaneous and nasal protothecosis in a goat. Vet. Pathol. 45:352-354.

Macêdo J.T.S.A., Riet-Correa F., Dantas A.F.M. \& Simões S.V.D. 2008b. Doenças de pele em caprinos e ovinos no semi-árido brasileiro. Pesq. Vet. Bras. 28(12):633-642.

Madewell B.R., Priester W.A., Gillette E.L. \& Snyder S.P. 1976. Neoplasms of the nasal passages and paranasal sinuses in domesticated animals as reported by 13 veterinary colleges. Am. J. Vet. Res. 37:851-856.

Martins J.E.C., Melo N.T. \& Heins-Vaccari E.M. 2005. Micoses subcutâneas, profundas e por leveduras, p.35-145. In: Ibid. (Eds), Atlas de Micologia Médica. Manole, São Paulo.

Méndez M.C., Riet-Correa F., Schild A.L. \& Ferreira J.L.M. 1987. Laboratório Regional de Diagnóstico: Doenças diagnosticadas no ano de 1986. Editora e Gráfica Universitária, UFPel, Pelotas, RS, p.2628.

Nayak D.R., Pillai S. \& Rao R. 2004. Rhinofacial zygomycose caused by Conidiobolus coronatus. Indian J. Otolaryn. Head Neck Surg. 56(3):225-227

Neves D.S., Furlan F.H., Lucioli J., Rocha T.S. \& Gava A. 2005. Tumor etmoidal em bovinos: Relato de caso. Arq. Bras. Med. Vet. Zootec. 57:9-10. Resumo)

Pedroso P.M.O., Dalto A.G.C., Raymundo D.L., Bezerra Júnior P.S., Bandara P.M., Oliveira E.C., Sonne L. \& Driemeier D. 2009. Rinite micótica nasofaríngea em um ovino Texel no Rio Grande do Sul. Acta Scientiae Veterinariae 37(2):181-185.

Penhit M.L., Van Der Lugt J.J., Henton M.M., Botha J.A. \& Stroebel 
J.C. 1994. A review of mycotic nasal granuloma em cattle, with a report of three cases. J. South Afr. Vet. Assoc. 65:179-183.

Pereira R.N., Perotia J.H., Dune A.C.C., Ferreira Lima I.G., Alessi A.C., Carvalho A.M., Canola P.A., Cattelan J.W. \& Canola J.C. 2005. Criptococose nasal em ovinos: relato de caso. Arq. Bras. Med. Vet. Zootec. 57(1):18. (Resumo)

Ramos C.I., Bellato V., Souza A.P., Avila V.S., Coutinho G.C. \& Dalagno C.A. 2006. Epidemiologia de Oestrus ovis (Díptera: Oestridae) em ovinos no Planalto Catarinense. Ciência Rural 36(1):173-178.

Ramos T.A., Norte D.M., Elias F. \& Fernandes C.G. 2007. Carcinoma de células escamosas em bovinos, ovinos e eqüinos: estudo de 50 casos no Rio Grande do Sul. Braz. J. Vet. Res. Anim. Sci. 44:5-13.

Ramos T.A., Souza A.B., Norte D.M., Ferreira J.L.M. \& Fernandes C.G. 2008. Tumores em animais de produção: aspectos comparativos. Ciência Rural 38(1):148-154

Ribeiro V.L.S., Oliveira C.M.B. \& Branco F.P.J.A. 1990. Prevalência e variações mensais das larvas de Oestrus ovis em ovinos no município de Bagé, RS, Brasil. Arq. Bras. Med. Vet. Zootec. 42(3):211221.

Ribeiro B.P. 2007. Míases, p.551-562. In: Riet-Correa F., Schild A.L., Lemos R.A.A. \& Borges J.R.J. (Eds), Doenças de Ruminantes e Eqüinos. Vol.1. 3를 ed. Pallotti, Santa Maria.

Riet-Correa F. 2007. Granuloma nasal em bovinos, p.635-637. In: RietCorrea F., Schild A.L., Lemos R.A.A. \& Borges J.R.J. (Eds), Doenças de Ruminantes e Eqüinos. Vol.2. $3^{\mathrm{a}}$ ed. Pallotti, Santa Maria.

Riet-Correa F., Cassal A.B., Scarsi R.M., Schild A.L. \& Mendes M.C. 1981. Carcinomas epidermóides em ovinos em um estabelecimento no Rio Grande do Sul. Pesq. Vet. Bras. 1(2):65-68.

Riet-Correa F., Schild A.L., Mendez M.C., Oliveira J.A., Turnes G. \& Gonçalves A. 1983. Atividades do Laboratório de Diagnóstico e doenças da área de influência no período 1978-1982. Editora Universitária, UFPel, Pelotas, p.32-34.

Riet-Correa F., Tabosa I.M., Azevedo E.O., Medeiros R.M.T., Simões S.V.D., Dantas A.A., Alves J.C., Nobre V.M.T., Athaylde A.C., Gomes A.A. \& Lima E.F. 2003. Doenças de ruminantes e eqüinos no semi-árido da Paraíba. Semi-árido em Foco, Patos, 1:4-111.

Riet-Correa F., Dantas A.F.M., Azevedo E.O., Simões S.D.V., Silva S.M.S., Vilela R. \& Mendonza L. 2008. Outbreaks of rhinofacial and rhinopahryngeal zygomycosis in sheep in Paraíba, northeastern Brazil. Pesq.Vet. Bras. 28(1):29-35.

Rissi D.R., Pierezan F., Oliveira Filho J.C., Fighera R.A., Irigoyen L.F.,
Kommers G.D. \& Barros C.S.L. 2010. Doenças de ovinos da região Central do Rio Grande do Sul: 361 casos. Pesq. Vet. Bras. 30(1):2128.

Santurio J.M., Argenta J.S., Schwendler S.E., Cavalheiro A.S., Pereira D.I.B., Zanette R.A., Alves S.H., Dutra V., Silva M.C., Arruda L.P., Nakazato L. \& Colodel E.M. 2008. Granulomatous rhinitis associated with Pythium insidiosum infection in sheep. Vet. Rec. 163:276-277.

Shnawa I.M.S. \& Nigam J.M. 1987. A note on cryptococcal mastitis in sheep. Indian Vet. Med. J. 7:175-176

Silva S.T.G., Souza J.C.A., Izael M.A., Riet-Correa F., Portela R.A., Dantas A.F., Mendonça C.L. \& Afonso J.A.B. 2009. Criptococose em Ovino: relato de caso. Anais VIII Congresso Brasileiro de Buiatria, Belo Horizonte, MG. Disponível em <http://www.vet.ufmg.br/cursos> Acesso em 9 nov. 2009 .

Silva S.M.M.S., Castro R.S., Costa F.A.L., Vasconcelos A.C., Batista M.C.S., Riet-Correa F. \& Carvalho E.M.S. 2007a. Conidiobolomycosis in sheep in Brazil. Vet. Pathol. 44:314-319.

Silva S.M.M.S., Castro R.S., Costa F.A.L., Vasconcelos A.C., Batista M.C.S., Riet- Correa F., Carvalho E.M.S. \& Lopes J.B. 2007b. Epidemiologia e sinais clínicos da conidiobolomicose em ovinos no estado do Piauí. Pesq. Vet. Bras. 27(4):184-190.

Souza F.A.L., Souza A.B., Sousa Júnior A., Costa F.A., Riet-Ccorrea F., Mendoza L., Carvalho E.M.S. \& Silva S.M.M.S. 2008. Pitiose em ovinos no estado do Piauí. Anais 35 Conbravet, Gramado, RS. Disponível em <http://www.sovergs.com.br/conbravet2008> Acesso em 8 jul. 2009.

Svara T., Gombac M., Vrecl M., Juntes P., Kostanjsek R., Pogacnik A. \& Pogacnik M. 2006. Enzootic nasal adenocarcinoma of sheep in Slovenia. J. Vet. Med. 53:26-29.

Stigger A.L., Riet-Correa G., Langohr I.M., Ilha M.R.S. \& Barros C.S.L. 2001. Granuloma nasal bovino. Ciência Rural 31(3):461-465.

Tokarnia C.H., Döbereiner J. \& Canela C.F.C. 1972. Tumor etmoidal enzoótico em bovinos no Estado do Rio de Janeiro. Pesq. Agropec. Bras. 7:41-46.

Trotte M.N.S., Santos I.B., Miranda L.H.M., Amorin A.R., Borges J.R.J. \& Menezes R.C. 2008. Histopatologia de lesões tumoriformes presentes na cavidade nasal de eqüídeos do Brasil. Ciência Rural 38:2535-2539.

Vilela R., Silva S.M.S., Riet-Correa F., Dominguez E. \& Mendonza L. 2010. Taxonomic and phylogenetic of Conidiobolus lamprauges recovered from infected sheep. J. Clinic. Microbiol. 48(2):427-432. 